\section{Using Pathway Modeling to Evaluate and Improve Student-Centered Teaching Practices in Co-Taught College Science Courses}

\author{
Xinnian Chen, ${ }^{\dagger \| *}$ John M. Redden, ${ }^{\dagger \|}$ Aiyana Bobrownicki, ${ }^{\ddagger}$ Julia Gill, $\$$ and \\ Mark J. Graham $\$$ \\ 'Department of Physiology and Neurobiology, University of Connecticut, Storrs, CT 06269; \\ ${ }^{\ddagger}$ Center for Teaching and Learning and \$STEM Program Evaluation and Research Laboratory \\ (STEM-PERL), Department of Ecology and Evolutionary Biology, Yale University, New Haven, \\ CT 06511
}

\begin{abstract}
Student-centered teaching practices such as active learning continue to gain momentum in college science education. Many instructors committed to these innovative practices transform their classrooms beyond the standard lecture. Nevertheless, widespread implementation of these practices is limited, because the learning benefits for students are often attained through increased instructional complexity to which many instructors cannot commit. When co-instructors are teaching the course, the level of commitment to building a student-centered classroom may be even more profound. For these reasons, new tools are needed to help instructors and co-instructors plan, organize, evaluate, and communicate their classroom innovations. Pathway modeling is a tool with the potential to fill this gap. Unlike curriculum mapping-which identifies academic content gaps, redundancies, and misalignments by examining a series of courses within a plan of study-course pathway modeling creates a visual map of a single course and reveals how teaching practices influence short-, mid-, and long-term student learning outcomes. This essay demonstrates how course pathway modeling can help co-instructors better represent the complexity of student-centered teaching practices. We include guides for creating course pathway models and discuss how this approach offers the potential to improve curricular design, course evaluation, student assessment, and communication between co-instructors.
\end{abstract}

\section{INTRODUCTION}

Student-centered teaching strategies such as active learning, formative assessment, and inclusivity are implemented less often in college science classrooms than has been anticipated; lecturing still dominates despite over a decade of investment in teaching reforms (Stains et al., 2018). While many science faculty are persuaded that teaching in a more active, engaging, and inclusive way is needed, there are many reasons why sustained change has lagged behind their recognition and desire for improvement. For example, the perceived barriers to restructuring an entire course, or even aspects of it, may feel overwhelming to faculty who have other academic obligations competing for their time and effort (Henderson and Dancy, 2007). Also, students sometimes resist classroom practices that require increased participation (Seidel and Tanner, 2013). These challenges can be compounded when course delivery requires buy-in and coordination from more than one instructor, as in co-taught courses (Morelock et al., 2017).

Co-teaching takes many forms. In some cases, two or more instructors collaborate on the design and execution of a course. In other situations, instructors collaborate on course design to a certain degree and then independently teach different sections. Previous work has shown that it is important not only to establish and maintain a
Erin L. Dolan, Monitoring Editor

Submitted Aug 5, 2019; Revised Jan 20, 2021; Accepted Jan 28, 2021

CBE Life Sci Educ June 1, 2021 20:es5

DOI:10.1187/cbe.19-07-0147

षThese authors contributed equally to this work. *Address correspondence to: Xinnian Chen (xinnian.chenauconn.edu).

(C) 2021 X. Chen, J. M. Redden, et al. CBE-Life Sciences Education (c) 2021 The American Society for Cell Biology. This article is distributed by The American Society for Cell Biology under license from the author(s). It is available to the public under an Attribution-Noncommercial-Share Alike 3.0 Unported Creative Commons License (http://creativecommons.org/licenses/ by-nc-sa/3.0).

"ASCB@" and "The American Society for Cell Biology ${ }^{\circledR}$ " are registered trademarks of The American Society for Cell Biology. 
strong communicative relationship, but also to conduct joint planning in a co-teaching setting (Quinlan, 1998; Letterman and Dugan, 2004; Morelock et al., 2017). Should any of the co-instructors decide to implement more student-centered pedagogies, the course complexity increases. Consequently, teaching in this way presents a new challenge for co-instructors to maintain consistency and clear communication within a course.

In the early stages of transitioning to more engaging teaching practices, instructors often rely on traditional assessment measures such as student feedback on end-of-course evaluations, quiz and exam grades, and other indicators like attendance or course participation (Garfield, 1994). Unfortunately, these may not be precise enough to gauge the success of their changes. Faculty may also fear the consequences of these measures stagnating (or worse, declining) and curtail their transformation efforts (Terenzini, 1989). This situation can be further exacerbated when co-teaching is involved, as disparities in experience, goals, and classroom challenges can lead to frustration or conflict. For instructors to develop the skills and confidence to teach in engaging ways, their reflection and evaluation practices must co-evolve alongside pedagogy (Darling-Hammond and Snyder, 2000). At a minimum, instructors must obtain a more complete picture of the overall student experience and find ways to represent the inherent complexities associated with evidence-based teaching (EBT) practices.

A meta-analysis by Henderson and colleagues argued that, in order to facilitate the adoption of EBT practices, in addition to focusing on "prescribed" activities such as professional training, successful transformations can also benefit from "emergent" reflective practices and vision sharing among stakeholders (Henderson et al., 2011). This can be particularly important for a co-taught course. Yet emergent reflective practices and vision sharing may be difficult to implement if co-instructors lack a way to "see" the inner workings of a course and respective teaching practices and communicate this to other course stakeholders. Once instructors visualize a course, it is easier for a range of stakeholders, including other instructors or department heads, to identify the resources and supports needed to implement the desired practices (Reeves et al., 2020).

From the program evaluation literature, we introduce a framework to better "see" the inherent complexity and the inner workings of how a science course functions-before, during, and after a given semester-as a novel way to monitor progress and address challenges that inevitably arise when co-teaching. Adopted from a systems approach to complex program evaluation (see Urban and Trochim, 2009), course pathway models are visual maps created to help co-instructors and various stakeholders of a course understand the multiple, interrelated priorities and components of a course. A pathway model is one part of a larger systems evaluation protocol that thoroughly describes a systems approach to evaluation (see Urban and Trochim, 2009; Cornell Office of Research on Evaluation [CORE], 2016).

Like the traditional logic model, the course pathway model helps stakeholders identify the short-, mid-, and long-term student outcomes that contribute to the overall course goal. Pathway models go a step beyond the traditional logic model (see Millar et al., 2001) by considering the multiple "systems"stakeholders such as the instructor, the students, the teaching assistants (TAs), the department, the institution-in which a program (or here, a course) resides (Urban and Trochim, 2009). The course pathway model that we propose is not derived from a single logic model; rather, it aims to integrate a network of logic models that describe the larger system in which a college science course exists. For example, a logic model of instructional practices created by the instructor can be visually linked to a logic model of student assessment. Across logic models, the intended outcomes of each model can then be integrated and made more visual via the pathway model approach (CORE, 2016).

To summarize, the ideas surrounding pathway modeling have been proposed in the program evaluation literature as a way to promote critical reflection (Buckley et al., 2015), so the course pathway model could similarly function to improve course design and evaluation. Once a course is visually mapped in this way, co-instructors will have a better opportunity to "see" where the important learning components are centered (referred to as "hubs") and then identify measures to assess intended short-, mid-, and, potentially, long-term course outcomes (see Urban and Trochim, 2009; CORE, 2016). We have found that, even in an established course, pathway modeling gives co-instructors a concrete way to identify new opportunities to enhance student learning or clarify obstacles that manifest as they transition out of their comfort zone into a new pedagogy.

What follows is a visualization and description of our approach to the course modeling process, its affordances, and its potential benefits to instructors and evaluation teams interested in assessing the effectiveness of teaching innovations.

\section{USING A COURSE MODELING APPROACH FOR DESIGN AND ASSESSMENT}

Creating a course pathway model generally involves initial preparation, model creation, model revision with key stakeholders, and model simplification. Applying this process iteratively allows for feedback loops to further connect intended course goals with course elements. We applied these procedures within a science course that we often co-teach, which features active learning and other forms of student-centered teaching. In developing our course pathway models, we prioritized:

1. Using clear and concise definitions of course goals that were aligned among instructors.

2. Incorporating feedback from multiple stakeholders, including faculty, TAs, students, and instructors of upperlevel courses to drive model evolution (see Supplemental Table 1).

3. Viewing the course within a complex environment (student prior knowledge variability, diversity of attitudes, physical classroom spaces, curricular requirements, etc.; see Supplemental Table 2).

4. Considering learning as a process, not an end point (e.g., final grades).

5. Creating an actionable, visual product that could be analyzed and implemented even while the course is in progress.

Next are specific considerations that we identified to assist with our model development process (see Figure 1) and some examples from our course. 
STEP I: INITIAL MODEL DEVELOPMENT

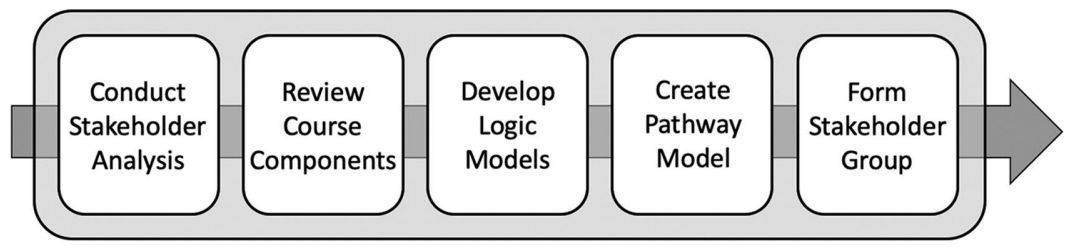

STEP 2: ITERATIVELY EXAMINE THE MODEL

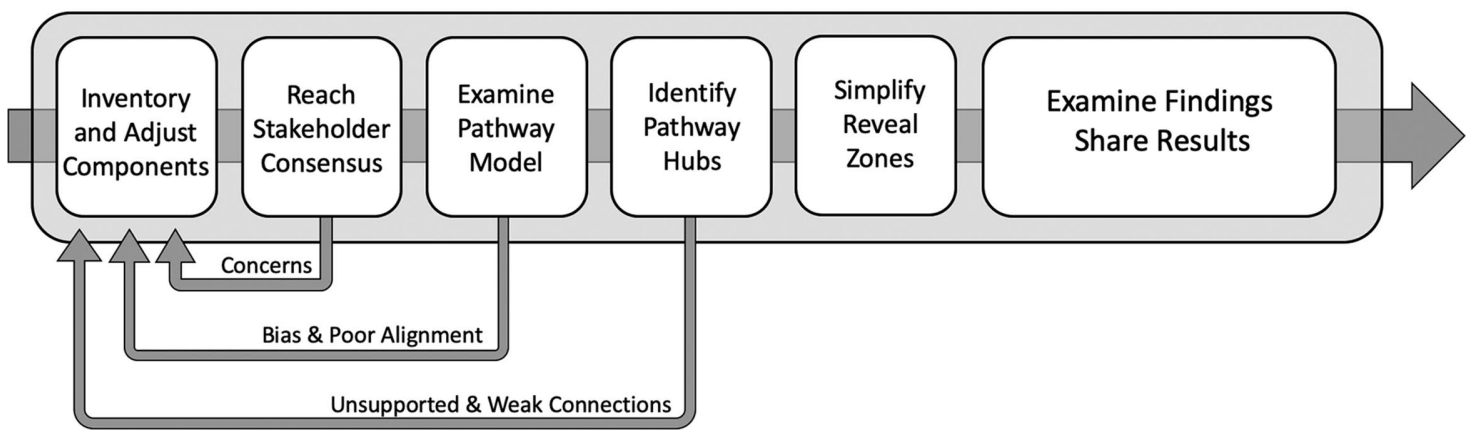

FIGURE 1. Course modeling general approach. Modeling steps are adapted from System Evaluation Protocol (SEP) for course modeling purposes.

The first step of this process is to conduct an initial review of the course that identifies as many elements of the course ecosystem as possible (see Supplemental Material for more detailed substeps). Essentially, this review should comprehensively capture the context, resources, and activities for a given course. Based upon our experience, we created an example template to help co-instructors identify the initial scope and focus (see Supplemental Table 3). Iterative examinations can increase or decrease complexity from this initial starting point. Similarly, when thinking about which course activities to include in the model, instructors should consider activities that happen within the classroom (e.g., classroom polling), as well as asynchronous components (e.g., homework, office hours, studying). We have created a worksheet to help instructors brainstorm these activities (see Supplemental Table 4).

Once this information has been collected, the next step is to have a course model builder, usually an instructor, enter this information into a standard logic model framework to identify inputs, activities, outputs, and outcomes (Cooksy et al., 2001). As an example, Figure 2 shows how a simple course activity supporting short- and medium-term outcomes from the logic model would be displayed in a pathway model.
As previously mentioned, it is likely that multiple logic models are needed to represent the complexity of the environment within which the course resides. The next step is where the course pathway model diverges from standard logic modeling. Currently, Evaluation Netway (www.evaluationnetway.org) and Mural (www.mural.co) are technological tools for modelers to integrate logic models and make connections between them to create a visual representation of their courses.

The newly created course pathway model can undergo iterative examination through a series of reviews conducted by the model builder and, if possible, other interested stakeholders. The visualization generated from the previous step supports assessment of the overall breadth of the model and the alignment between course components. To ensure that alignment has been achieved, this step can benefit from a working group that includes other stakeholders, such as students, colleagues, and/or evaluators, in addition to the course instructors. The working group should examine whether the course activities, resources, and supports provided by the instructors are sufficient to reach the course goals. For example, does the inclusion of diverse undergraduate mentors create a sense of community that might ultimately instill a sense of belonging in science?
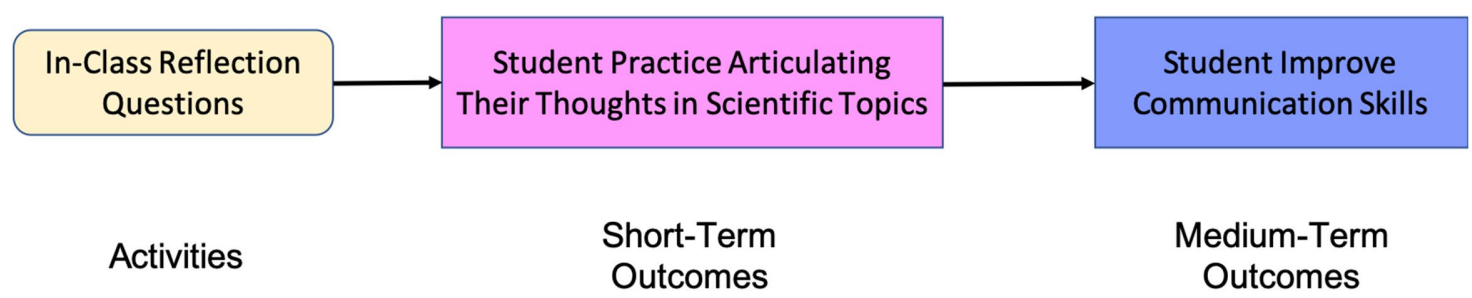

\section{Medium-Term Outcomes}

FIGURE 2. Example of pathway model connections. Cream box represents a class activity, while pink and purple boxes represent shortand mid-term outcomes, respectively. 
Importantly, the working group should also identify unsupported assumptions made by the primary model builder when establishing the logical relationships used by the model. For example, one question may be: does the implementation of an activity guarantee improved learning even if student engagement is minimal, or class attendance is low? When the concerns that arise from this step have been adequately addressed, a final course model is created that provides a comprehensive view of the course.

The finished model will likely be complex in order to reflect the many components of a student-centered course. To communicate the main model findings effectively for a broader group of stakeholders, we recommend simplifying the model into "zones" as a final step (see Reeves et al., 2020). A simplified model is not intended to replace the comprehensive model generated in the previous step, but rather to exist in parallel and provide an alternate, more digestible view. An instructor could use a simplified model as a visual aid to facilitate TA training, convey the logistics of the course to another instructor teaching a pre- or co-requisite course, or advocate for resources in a course.

\section{EXAMPLE: MODELING TO IMPROVE AN ANATOMY AND PHYSIOLOGY COURSE Context and Participants for the Adoption of the Course Pathway Model}

In 2009 and 2015, two departmental colleagues (X.C. and J.R.) who teach Anatomy and Physiology at the University of Connecticut participated in the Summer Institutes on Scientific Teaching (SI), a national instructor training program that seeks to increase the use of "scientific teaching" in undergraduate science, technology, engineering, and mathematics (STEM) classrooms. "Scientific teaching" is a term used to describe a student-centered pedagogical approach that incorporates active learning, formative assessment, and inclusive teaching practices as core elements (Handelsman et al., 2007). These practices are known as evidence-based teaching, or EBT, strategies, and EBT reflects the spirit of scientific research being based on existing evidence from peer-reviewed literature. After the SI training, one of the instructors (X.C.) made a substantial effort to implement EBT practices in her co-taught two-semester anatomy and physiology course offered to biology majors. Although student participation and feedback were generally positive after increasing the use of EBT in the course, student exam performance did not significantly increase compared with previous years. After sharing these findings, evaluators affiliated (M.G. and A.B.) with the SI introduced the instructor to pathway modeling as a way to better understand her course's inner structure and outcomes. Her departmental colleague (J.R.), who also participated in the SI, became a collaborator in the pathway modeling project, because he wanted to expand his pedagogical toolbox. The colleague co-teaches a section of the course in the summer and a related course for nonmajors during the academic year. As such, this Essay takes an inclusive view of co-teaching, recognizing that, although the instructors who undertook pathway modeling co-teach different sections of the same course, they both benefited from the vision sharing and course goal-alignment process spurred by pathway modeling. They relayed their insights to their teaching partners and departmental colleagues to facilitate discussion and standard- ize implementation of course innovations resulting from the model.

\section{Initial Pathway Model Construction}

Once the instructors became familiar with the overall process and visualization tools, they created the initial course model, a process that took about 5-7 hours in total to draft, spread out over several 1- to 2-hour meetings focused on brainstorming and model refinement. An evaluator (A.B.) familiar with the modeling process periodically reviewed the overall flow of the course pathway model with them. Through these review meetings, they realized that the model did not capture all components of the course. For example, the contributions of TAs were absent, because the instructors had focused only on their own practices. They then revised the model and shared it with other stakeholders (e.g., TAs during their weekly meetings). The expanded working group used the model in addition to student evaluation and assessment data to reflect on miscommunications and assumptions that were made designing the course. The co-instructors set up a 1-hour standing meeting throughout the semester, making the overall time investment up to this point approximately 15 hours. Using the model, the instructors made several important course improvements, and the model was further revised. Eventually, revisions reached a plateau as the instructors worked to optimize the course, but they realized it can continue to evolve and be revisited as needed. The full model is provided in Supplemental Figure 1, and a suggested list of stakeholders and their appropriate roles in the process is provided in Figure 3.

As illustrated in the full pathway model (see Supplemental Figure 1), the model has a general left-to-right flow, with course activities linked to short-term outcomes (e.g., explicit discussion of scientific teaching leads to students learning about metacognition; Tanner, 2012). Each short-term outcome must lead to either another short-term outcome or to medium-term outcome(s): for example, students learning about metacognition leads to students reviewing their learning process. As a rule, a short-term outcome cannot directly connect with a longterm outcome (see Urban and Trochim, 2009; CORE, 2016). In turn, medium-term outcomes contribute to other medium-term outcomes or long-term outcomes (e.g., students metacognitively reviewing their learning process leads to improved student learning). In Figure 2, we provide a visual from the model that demonstrates these relationships linearly. Importantly, when engaging in this part of the mapping process, be judicious so as not to make too few or too many connections.

Due to the overlapping and highly interconnected nature of pathway model's boxes and arrows, there will likely be convergence and divergence in any given model. Convergence occurs when multiple activities lead to the same outcome. For example, there are multiple activities that support the short-term outcome "students practice articulating their thoughts on science topics." Similarly, multiple short-term outcomes contribute to the same medium-term outcome, such as, "students improve study skills." On the other hand, divergence occurs when one activity leads to multiple outcomes. For instance, the box titled "students perceive that classroom discussion is normal" leads to multiple medium-term outcomes, including "students learn challenging topics" and "students ask questions in multiple settings" (e.g., in lecture vs. lab). 


\begin{tabular}{|c|c|c|c|c|}
\hline Suggested Stakeholder & Suggested Role & $\begin{array}{c}\text { Suggested } \\
\text { Recruitment Strategy }\end{array}$ & $\begin{array}{l}\text { Approximate } \\
\text { Time Investment }\end{array}$ & Motivation to Participate \\
\hline Co-instructor & Primary model builder & Intrinsic motivation & $10-15$ hours & $\begin{array}{l}\text { Improved efficiency in course } \\
\text { development, revision, and } \\
\text { assessment; improved } \\
\text { communication and alignment } \\
\text { between stakeholders }\end{array}$ \\
\hline Co-instructor & Secondary model builder & Intrinsic motivation, collegiality & $8-10$ hours & $\begin{array}{l}\text { Improved efficiency in course } \\
\text { development, revision, and } \\
\text { assessment; improved } \\
\text { communication and alignment } \\
\text { between stakeholders. }\end{array}$ \\
\hline Graduate TA & Working group & Requirement of position & $1-2$ hours & $\begin{array}{l}\text { Better understanding of teaching, } \\
\text { professional development, } \\
\text { improved classroom experience }\end{array}$ \\
\hline Undergraduate student & $\begin{array}{l}\text { Working group/ } \\
\text { benefactor }\end{array}$ & $\begin{array}{l}\text { Extra credit or independent study } \\
\text { opportunity, announcement in class or } \\
\text { via learning management system }\end{array}$ & $1-2$ hours & $\begin{array}{l}\text { Better understanding of course and } \\
\text { improved context for curriculum }\end{array}$ \\
\hline $\begin{array}{l}\text { Department head/ } \\
\text { administrator }\end{array}$ & Benefactor & $\begin{array}{l}\text { Internal/external department review, } \\
\text { PTR process, departmental retreat }\end{array}$ & $<30$ minutes & $\begin{array}{l}\text { Reporting, resource allocation, } \\
\text { department advocacy }\end{array}$ \\
\hline
\end{tabular}

\section{FIGURE 3. Potential stakeholders. Stakeholder groups will vary depending on the type of course being modeled.}

Furthermore, certain outcomes are important intermediates that serve as "hubs" (Urban and Trochim, 2009). The pathway model visualization allows for easy identification and analysis of these key measures and instructional milestones. For an intermediate to qualify as a "hub" in the map, the instructors decided that there needed to be at least four inputs and one output. The criterion for a hub is somewhat arbitrary, because it will depend on the overall complexity of the model. The key is to identify intermediates that serve important outcomes within the model and examine how they are supported. Using this criterion, several important hubs were identified in the model, including students ask questions in multiple settings, students receive formative feedback from their instructor on an ongoing basis, TAs revise and improve their lesson plans and teaching methods, and improved student learning. To facilitate further discussion of the model, the instructors focused on these areas independently. In Figure 4, we provide an example showing some of the inputs into the "improved student learning" hub, but readers can refer to the full model in Supplemental Figure 1.

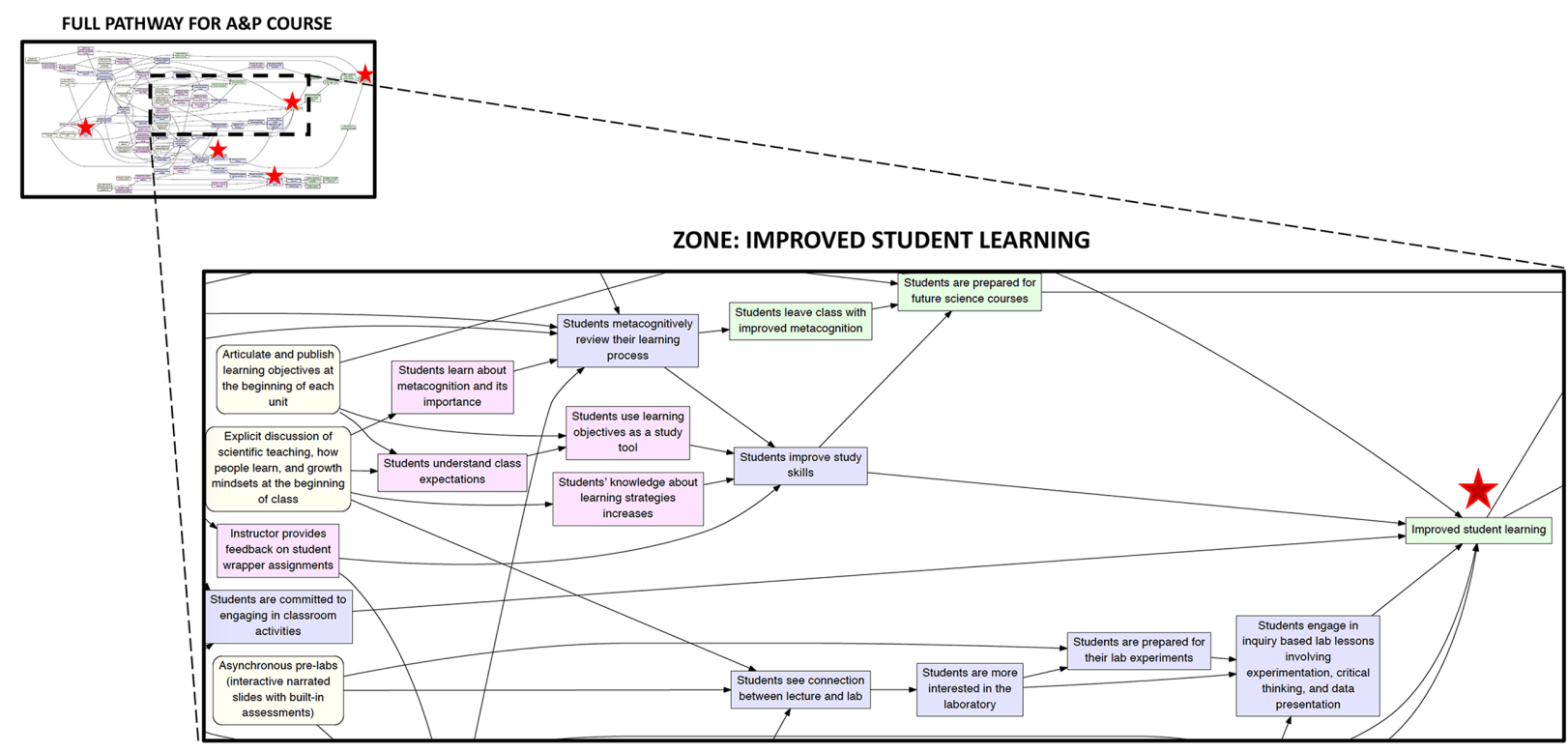

Activities

Short-Term Outcome

Medium-Term Outcome

Long-Term Outcome

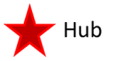

FIGURE 4. Identification of key hubs. Key outcome hubs were identified based on the number of arrows connected to a particular outcome. Cream boxes represent class activities, while pink, purple, and green boxes represent short-, mid-, and long-term outcomes, respectively. 


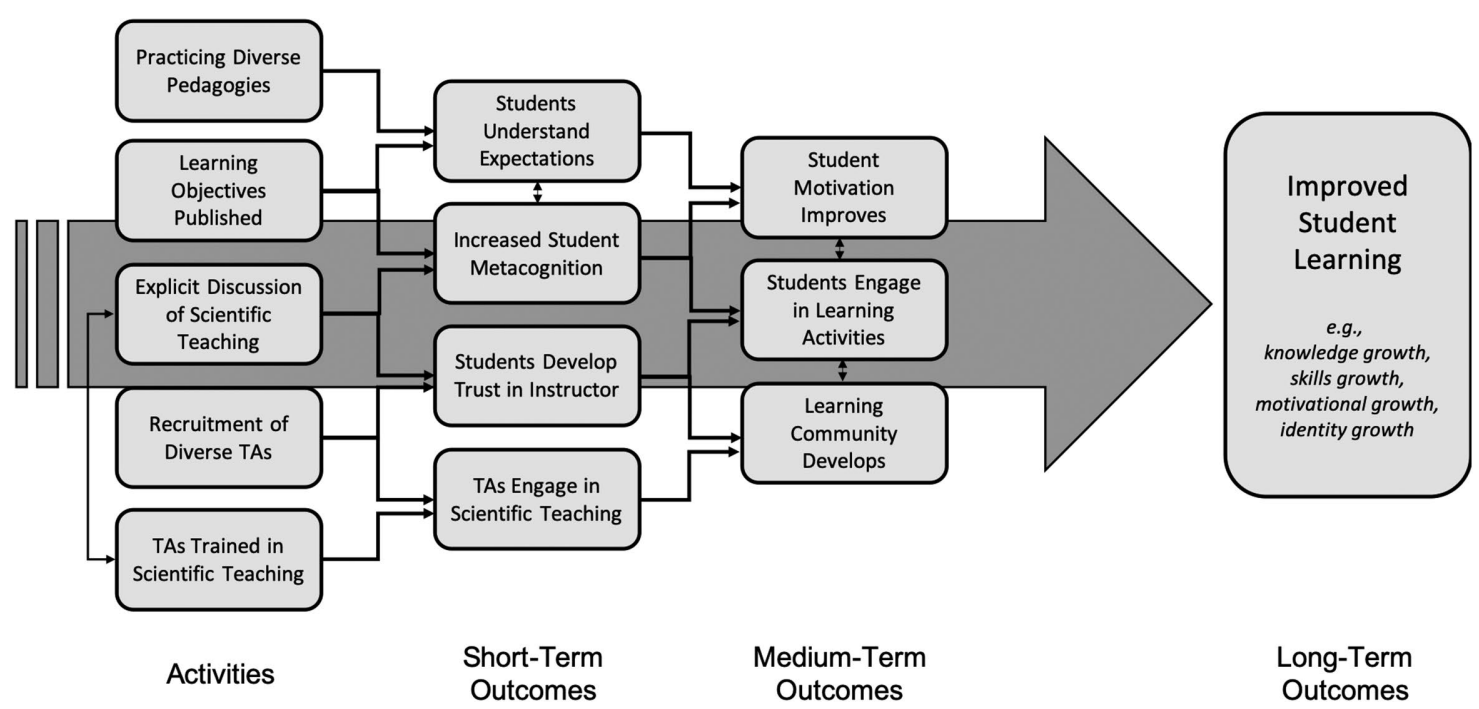

FIGURE 5. Simplified course pathway model. Themes of activities and short-, mid-, and long-term outcomes are summarized and presented in columns.

\section{Prepare the Model for Broader Communication}

Before discussing the model with other stakeholders and receiving their input, the instructors "cleaned up" and "simplified" the model to illustrate the major takeaways. Figure 5 describes this process of iterative examination and simplification. They worked together on this task, which took an additional 2 hours. The time investment is likely to correlate with the quantity and complexity of model inputs. This illustration broadly captures three themes emerging from the course pathway model-student motivation, engagement, and support-that the literature suggests can support the ultimate long-term goal of improved student learning. Motivation, defined here as a student's desire to participate in the learning process (Lumsden, 1994), improves student engagement (Pintrich, 1991); likewise, a learning community can strengthen a student's sense of belonging, further improving motivation and engagement, and can lead to more sustained college student persistence in the sciences (Graham et al., 2013). These elements-motivation, engagement, and support from the learning community-are highly interconnected, and the mapping process allowed us to see the details of how each can be achieved (Zumbrunn et al., 2014). For example, when considering the third pathway of support from the learning community, an important component is the contribution of TAs. Building the pathway model lent the instructors the major insight that the strategic involvement of TAs required appropriate training and a shared vision beyond what had originally been anticipated.

\section{Use the Pathway Model to Improve the Course}

When examining the pathways, it became clear that an existing assumption was that once the instructors provided students with engaging activities, students would feel more motivated, which would lead to improved learning (Freeman et al., 2014). Through the course pathway model, however, the instructors realized that this assumption was flawed, as many students do not see the connection between class activities and their learning and may feel uncomfortable participating in group work (see Cavanagh et al., 2016). As a result, they altered the course (and the pathway model) by strengthening and improving the three components of the course (Welsh, 2012).

The first course improvement made was based on the realization that a deeper, more intentional focus on student buy-in to scientific teaching practices was needed to promote student engagement (Cavanagh et al., 2016; Finelli et al., 2018). Deliberative practices, such as discussing the cognitive science of learning with students, became a critical focus for the instructors (Seidel and Tanner, 2013). The instructors determined that, in order for students to feel more motivated to engage with "evidence-based" learning activities, instructors must provide a convincing and transparent rationale for why certain course activities-like group work-are required (Bacon et al., 1999; Straits and Wilke, 2003; Strobel and van Barneveld, 2009; Felder, 2011; Tharayil et al., 2018). As a result, the co-instructors developed new activities that focused on scientific teaching training for students and TAs and included these activities in the pathway model.

The second course improvement made was based upon the realization that the misalignment of assessment practices and the short-, medium-, and long-term goals identified in the course pathway model could lead to a lack of motivation among students (Donohue and Richards, 2009; Bentley et al., 2011). By working together to examine the model, the co-instructors realized that they needed to align their teaching practices with student assessment. For example, they discovered that, despite their shared vision for students to work together in class, they differed in their approaches to achieve this end. This caused confusion and disinterest among students, and it also confounded grading. As a result, they introduced new components to their class and adjusted the summative assessment scheme to better reflect their mutual course activities and goals. For example, team-based learning and participation are now graded components of the course, whereas before student grades were determined largely by exam performance.

The third course improvement made was based on several new insights about the long-term outcomes identified in the course pathway model. For example, for student learning to 
improve in meaningful ways: 1) students need to finish the course with skills to succeed in future science courses (see American Association for the Advancement of Science [AAAS], 2011); 2) students need to gain confidence learning challenging topics (Ballen et al., 2017); and 3) students need to find ways to identify themselves as members of the broader science community (Carlone and Johnson, 2007; Trujillo and Tanner, 2014). Building "science identity" was consistently an important course goal, and yet, through course pathway modeling, the co-instructors identified that there was no support for this goal in their current course structure.

One reason that students may not feel they belong in a course is because they do not think that they contribute to class activities (Kearney et al., 1991; Seidel and Tanner, 2013; Finelli et al., 2018). Therefore, the instructors created opportunities for all students to voice their opinions, provide suggestions, and receive feedback on how their suggestions were incorporated. They now explicitly discuss in class how important it is to receive feedback from all students regardless of where they are in the learning process. Additionally, developing a science identity is particularly challenging for underrepresented minority students (URMs) (Hurtado et al., 2010; Chemers et al., 2011). In subsequent semesters, there was a renewed emphasis on building students' science identity. The co-instructors have, for example, focused on more consciously recruiting URMs to become undergraduate TAs to facilitate learning and motivate other URMs through near-peer interactions and mentoring (Strayhorn, 2010).

\section{DISCUSSION}

Science courses exist within complex systems, and course pathway models represent their complexity by integrating a network of short-, mid-, and long-term outcomes across contexts and stakeholders. The goal is for the instructor or co-instructors to better "see" interrelated aspects of a course. The unique feature of a college science course pathway model is that it is a graphical representation of the instructional complexity between activities and outcomes that highlights how a course seeks to achieve its goals. It provides an invaluable foundation for making sound improvements or evaluation decisions (see Urban and Trochim, 2009).

Although instructors can create valuable course pathway models independently, we have benefited from collaborating with evaluators. In particular, evaluators helped the instructors expand their model to include motivational components and provided a framework to explain the steps that should be followed to achieve the desired outcomes of active learning. Instructors working independently would benefit from possessing a working knowledge of common educational terms and logic models before embarking on this process (see Millar et al., 2001; Miller and Tanner, 2015). Guidance in these areas may be sought from on-campus centers for teaching and learning, if available. To make the process of model building feasible for a novice user, we distilled some key considerations into the supplemental worksheets, recognizing that some instructors will not be able to work with an evaluator (see Supplemental Materials). If an instructor seeks more resources on pathway modeling, we suggest browsing the open-access Systems Evaluation Protocol (CORE, 2016) and other resources provided in Supplemental Table 5.
We encourage using the course pathway model, because it provides many benefits to instructors. First, the course pathway model increases efficiency in curricular review and redesign. The Vision and Change movement (AAAS, 2011) has transformed many college science courses by encouraging the adoption of backward design, that is, a more goal-oriented way to evaluate and redesign science courses (Wiggins and McTighe, 2005). As Henderson and his colleagues have suggested, it is important to include "emergent" reflective practices and vision sharing among stakeholders, and course modeling facilitates this process (Henderson et al., 2011). For example, in reviewing the course through the perspectives of building a pathway model, the instructors identified several elements that are important for student success and developed new ways to reinforce them. This would have been far less obvious without the course pathway model as a reference point. In particular, by constructing and reviewing the course pathway model with stakeholders, the instructors gained insights that helped them to: 1) address student misconceptions; 2) promote studentinstructor interactions; and 3) increase student engagement in the learning process.

Course pathway modeling also improved communication among stakeholder groups. Among college science educators, there has been renewed discussion on teaching effectiveness as well as increased emphasis on EBT. As a result, there is a growing realization that institutional culture and student commitment to EBT are critical elements of STEM education transformation (Henderson et al., 2011). Developing a shared vision among all stakeholders (e.g., instructors, administrators, students) will advance EBT efforts at the departmental and institutional levels. Nevertheless, it can be difficult for each stakeholder group to communicate what they do in a systematic and substantive way to other stakeholders. Course pathway modeling provides a visual tool to facilitate this dialogue, particularly with regard to course goals and their implementation. Instructors may already have logic models for their courses and, if so, they should focus on the columns for "activities" and "outcomes" to think more deeply about additional logic models across the various systems within which a course resides. They can then work to make connections in a course pathway model that link activities and outcomes within the system.

Most importantly, the course model improves communication among co-instructors. Many science courses are co-taught by two or more instructors. Although many teaching partners frequently discuss various components of a course, it is rare for them to share their own visions of the course in a systematic and comprehensive way. Moreover, there may be a disconnect between what instructors intend do in class and what they actually do. One of the most direct benefits of creating a course pathway model is to clarify terms and practices used differently by different instructors. The model is a tool that enables the sharing and discussion of ideas, merging of visions, and unification of instructor practices. In many cases, the course pathway model can be used to justify class activities by illustrating how they fit into overall learning goals. The instructors consider formative student feedback important for student learning; however, they implemented different strategies to collect and respond to it. For example, one instructor relied heavily on clicker questions and other active-learning strategies, whereas the other instructor preferred to solicit verbal feedback from students in class, during 
office hours, and online through the course's learning management system. By building the course pathway model, the co-instructors became aware of each other's practices which promoted discussions that would not otherwise have happened.

Course pathway modeling also allows co-instructors to identify when certain course elements are missing or only sporadically present, because not all instructors are implementing them or are in agreement about their importance. For example, despite the co-instructors' shared vision to increase diversity and representation in their course, they did not specifically recruit undergraduate TAs from diverse backgrounds when launching an undergraduate TA program. The visual aid provided by the pathway model highlighted that this goal was largely unsupported, because we did not adequately account for inclusivity. Moreover, modeling allowed the instructors to work together to create multiple ways to ensure these key "hubs" were supported adequately, even if different instructors are teaching different class sessions, or different instructors are teaching different lesson units.

Given how pathway modeling has been applied in the evaluation literature as a method to better understand a program's design (Urban and Trochim, 2009), we propose that there is similar potential for pathway modeling to improve course design and evaluation. The pathway model can bridge the conversations between instructors and science education researchers/evaluators (e.g., clarify terminologies, explain practices). Perhaps more importantly, even for experienced evaluators, a holistic and comprehensive course map can facilitate the identification of various theoretical frameworks (i.e., motivation, critical-thinking skills development) to inform the selection of measures to capture and explain the mechanisms underlying the observed teaching practices. For example, one area of the course model may focus on activities or outcomes best described through learning theories, while other areas might focus on student identity building, faculty development, TA training, or institutional support. The course map considers the complex ecosystem and life cycle of the course and is capable of capturing various inputs to the system.

Once completed and simplified, the course pathway model may provide additional benefits for a variety of stakeholders. For students, a simplified course model, in addition to a traditional syllabus, could provide them with a clear road map of how learning activities will contribute to their success in the course. For instructors, the course model provides a way to justify resource allocation to administrators by visualizing impressive course features and desired outcomes. For administrators, the course model is a comprehensive way to identify or reward innovative teaching methods to maximize program effectiveness. In an early iteration of the model, nearly all of the components were instructor focused. Following discussion within the expanded working group, the newest iteration of the course map demonstrates how multiple stakeholders make valuable contributions to the course goals. The instructors use this in dialogue with their undergraduate TAs to generate enthusiasm around teaching and with their undergraduate students to help them understand the instructors' vision for their success in the course.

\section{LIMITATIONS}

There are several limitations to the present work. Although qualitative and anecdotal feedback provided by course evalua- tions has been positive, we have not yet evaluated how the course changes spurred by pathway modeling have impacted students in our co-taught class. While the education literature suggests that there are inherent benefits to improving student motivation, engagement, and belonging, more formal and targeted analysis of student outcomes is needed. While course pathway modeling by itself does not automatically improve student outcomes, vision sharing can help co-instructors communicate and realize their mutual course goals, whatever they may be. To our knowledge, however, there are no published examples of course pathway modeling in college sciences courses. Without additional adoption, it is still an open question whether the benefits we observed can be extended to other courses. Despite these limitations, the course pathway model has created an opportunity to make systematic changes to a co-taught anatomy and physiology course. It has also given instructors and evaluators a new perspective for evaluating those changes.

\section{CONCLUSION}

Pathway models have been used to identify research questions and develop evaluation plans for large-scale, complex educational programs. Here, we broaden the application of this approach to the development and evaluation of co-taught college science courses. This is not to say that other course evaluation methods should be replaced by course pathway modeling. Rather, we suggest that reflecting on a visual representation of the complex environment within which a course exists-created from a collaboration of instructors, evaluators, and students-can shed light on course elements that might otherwise go unnoticed. From this perspective, course pathway modeling is an approach to help those interested in advancing course evaluation and assessment by providing a visual tool to identify measures and outcomes of primary interest. In this case, instructors used course mapping to identify and prioritize areas for improving teaching. This new addition to the college science course evaluation toolbox offers co-instructors and discipline-based education researchers a medium to evaluate courses in a novel way. Instead of just measuring the learning outcomes, the course modeling approach facilitates a rich and robust experience for all stakeholders by holistically monitoring the teaching process, the motivations behind it, and potential confounding factors. As more institutions look for new ways to evaluate teaching, it is our hope that the course pathway model approach can contribute to this national initiative.

\section{ACKNOWLEDGMENTS}

Research that contributed in part to this Essay was made possible through a National Science Foundation Transforming Undergraduate Research in the Sciences (TUES) grant (NSF no. 323079 and NSF no. 1323258). Support for the Summer Institutes on Scientific Teaching was made possible through funding from the Howard Hughes Medical Institute. We thank our collaborators on this grant, including Jane Cameron Buckley, Brian Couch, Mary Durham, Jennifer Frederick, Monica Hargraves, Claire Hebbard, Jennifer Knight, and William Trochim. We thank our course co-instructors and students who participated in the project as well as our instructor colleagues from other institutions who were willing to try course pathway modeling. We appreciate the valuable feedback from Melanie Bauer and three anonymous reviewers on earlier versions of this Essay. 


\section{REFERENCES}

American Association for the Advancement of Science. (2011). Vision and change in undergraduate biology education: A call to action. Washington, DC.

Bacon, D. R., Stewart, K. A., \& Silver, W. S. (1999). Lessons from the best and worst student team experiences: How a teacher can make the difference. Journal of Management Education, 23(5), 467-488.

Ballen, C. J., Wieman, C., Salehi, S., Searle, J. B., \& Zamudio, K. R. (2017). Enhancing diversity in undergraduate science: Self-efficacy drives performance gains with active learning. CBE-Life Sciences Education, 16(4), $\operatorname{ar} 56$.

Bentley, F. J. B., Kennedy, S., \& Semsar, K. (2011). How not to lose your students with concept maps. Journal of College Science Teaching, 41(1) 61-68.

Buckley, J., Archibald, T., Hargraves, M., \& Trochim, W. M. (2015). Defining and teaching evaluative thinking: Insights from research on critical thinking. American Journal of Evaluation, 36(3), 375-388.

Carlone, H. B., \& Johnson, A. (2007). Understanding the science experiences of successful women of color: Science identity as an analytic lens. Journal of Research in Science Teaching, 44(8), 1187-1218.

Cavanagh, A. J., Aragón, O. R., Chen, X., Couch, B. A., Durham, M. F., Bobrownicki, A., ... \& Graham, M. J. (2016). Student buy-in to active learning in a college science course. CBE-Life Sciences Education, 15(4), ar76.

Chemers, M. M., Zurbriggen, E. L., Syed, M., Goza, B. K., \& Bearman, S. (2011). The role of efficacy and identity in science career commitment among underrepresented minority students. Journal of Social Issues, 67(3), 469-491.

Cooksy, L. J., Gill, P., \& Kelly, P. A. (2001). The program logic model as an integrative framework for a multimethod evaluation. Evaluation and Program Planning, 24(2), 119-128.

Cornell Office of Research on Evaluation. (2016). Guide to the Systems Evaluation Protocol. Retrieved May 20, 2019, from https://core.human.cornell.edu/research/systems/protocol/index.cfm

Darling-Hammond, L., \& Snyder, J. (2000). Authentic assessment of teaching in context. Teaching and Teaching Education, 16(5-6), 523-545.

Donohue, S., \& Richards, L. (2009). Factors affecting student attitudes towards active learning activities in a graduate engineering statistics course. Paper presented at: 39th ASEE/IEEE Frontiers in Education Conference (San Antonio, TX).

Felder, R. M. (2011). Hang in there! Dealing with student resistance to learner-centered teaching. Chemical Engineering Education, 45(2), 131-132.

Finelli, C. J., Nguyen, K., DeMonbrun, M., Borrego, M., Prince, M., Husman, J., ... \& Waters, C. K. (2018). Reducing student resistance to active learning Strategies for instructors. Journal of College Science Teaching, 47(5), 80-91.

Freeman, S., Eddy, S. L., McDonough, M., Smith, M. K., Okoroafor, N., Jordt, H., \& Wenderoth, M. P. (2014). Active learning increases student performance in science, engineering, and mathematics. Proceedings of the National Academy of Sciences USA, 111(23), 8410-8415. doi: 10.1073/ pnas.1319030111

Garfield, J. B. (1994). Beyond testing and grading: Using assessment to improve student learning. Journal of Statistics Education, 2(1). doi: 10.1080/10691898.1994.11910462

Graham, M. J., Frederick, J., Byars-Winston, A., Hunter, A. B., \& Handelsman, J. (2013). Increasing persistence of college students in STEM. Science 341(6153), 1455-1456. doi: 10.1126/science.1240487

Handelsman, J., Miller, S., \& Pfund, C. (2007). Scientific teaching. New York: Freeman.

Henderson, C., Beach, A., \& Finkelstein, N. (2011). Facilitating change in undergraduate STEM instructional practices: An analytic review of the literature. Journal of Research in Scientific Teaching, 48(8), 952-984.

Henderson, C., \& Dancy, M. H. (2007). Barriers to the use of research-based instructional strategies: The influence of both individual and situational characteristics. Physical Review Special Topics-Physical Education Research, 3(2), 020102.

Hurtado, S., Newman, C. B., Tran, M. C., \& Chang, M. J. (2010). Improving the rate of success for underrepresented racial minorities in STEM fields: In- sights from a national project. New Directions for Institutional Research, 2010(148), 5-15

Kearney, P., Plax, T. G., \& Burroughs, N. F. (1991). An attributional analysis of college students' resistance decisions. Communication Education, 40(4), 325-342.

Letterman, M. R., \& Dugan, K. B. (2004). Team teaching a cross-disciplinary honors course: Preparation and development. College Teaching, 52(2), 76-79.

Lumsden, L. S. (1994). Student Motivation to Learn. ERIC Digest, 92 ED370200

Millar, A., Simeone, R. S., \& Carnevale, J. (2001). Logic models: A systems tool for performance management. Evaluation and Program Planning, 24(1), $73-81$.

Miller, S., \& Tanner, K. D. (2015). A portal into biology education: An annotated list of commonly encountered terms. CBE-Life Science Education, 14(2), fe2. doi: 10.1187/cbe.15-03-0065

Morelock, J. R., Lester, M. M., Klopfer, M. D., Jardon, A. M., Mullins, R. D., Nicholas, E. L., \& Alfaydi, A. S. (2017). Power, perceptions, and relationships: A model of co-teaching in higher education. College Teaching 65(4), 182-191. doi: 10.1080/87567555.2017.1336610

Pintrich, P. R. (1991). A manual for the use of the Motivated Strategies for Learning Questionnaire (MSLQ). Ann Arbor, MI: National Center for Research to Improve Postsecondary Teaching and Learning.

Quinlan, K. M. (1998). Promoting faculty learning about collaborative teaching. College Teaching, 46(2), 43-47.

Reeves, P. M., Bobrownicki, A., Bauer, M., \& Graham, M. J. (2020). Communicating complex STEM program evaluation to diverse stakeholders. CBELife Sciences Education, 19(2), es4.

Seidel, S. B., \& Tanner, K. D. (2013). "What if students revolt?"-Considering student resistance: Origins, options, and opportunities for investigation. CBE-Life Sciences Education, 12(4), 586-595.

Stains, M., Harshman, J., Barker, M. K., Chasteen, S. V., Cole, R., DeChenne-Peters, S. E., ... \& Young, A. M. (2018). Anatomy of STEM teaching in North American universities. Science, 359(6368), 1468

Straits, W. J., \& Wilke, R. R. (2003). Activities-based astronomy: An evaluation of an instructor's first attempt and its impact on student characteristics. Astronomy Education Review, 2(1), 46-64.

Strayhorn, T. L. (2010). Work in progress-Social barriers and supports to underrepresented minorities' success in STEM fields. Paper presented at 40th ASEE/IEEE Frontiers in Education Conference (Washington, DC) $\mathrm{S} 1 \mathrm{H}-1-5$.

Strobel, J., \& van Barneveld, A. (2009). When is PBL more effective? A meta-synthesis of meta-analyses comparing PBL to conventional classrooms. Interdisciplinary Journal of Problem-Based Learning 3(1), 44.

Tanner, K. D. (2012). Promoting student metacognition. CBE-Life Sciences Education, 11(2), 113-120.

Terenzini, P. T. (1989). Assessment with open eyes: Pitfalls in studying student outcomes. Journal of Higher Education, 6(60), 644-664

Tharayil, S., Borrego, M., Prince, M., Nguyen, K. A., Shekhar, P., Finelli, C. J., \& Waters, C. (2018). Strategies to mitigate student resistance to active learning. International Journal of STEM Education, 5(1), 7

Trujillo, G., \& Tanner, K. D. (2014). Considering the role of affect in learning: Monitoring students' self-efficacy, sense of belonging, and science identity. CBE-Life Sciences Education, 13(1), 6-15

Urban, J. B., \& Trochim, W. (2009). The role of evaluation in research-Practice integration working toward the "golden spike." American Journal of Evaluation, 30(4), 538-553.

Welsh, A. J. (2012). Exploring undergraduates' perceptions of the use of active learning techniques in science lectures. Journal of College Science Teaching, 42(2), 80-87.

Wiggins, G., \& McTighe, J. (2005). Understanding by design. Alexandria, VA Association for Supervision and Curriculum Development.

Zumbrunn, S., McKim, C., Buhs, E., \& Hawley, L. R. (2014). Support, belonging, motivation, and engagement in the college classroom: A mixed method study. Instructional Science, 42(5), 661 